science. Since a higher degree of explanatory power is the aim of any academic discipline, the agreement on this point undoubtedly is the decisive criterion.

Fred Kort University of Connecticut

\section{TEACHING BIOPOLITICS}

In each issure of Politics and the Life Sciences, we plan to publish course descriptions and syllabi covering topics in biopolitics. We invite comments about experiences teaching biosocial science, as well as any materials that might have been developed. We would also like to hear about the responses of colleagues and students to these efforts.

We include here a description of a new set of courses developed from a biopolitical perspective and offered by the biology, anthropology, and government departments of Dartmouth College.

\section{A Currlcular Experiment:The Nature of Human Nature}

Many students have complained about the fragmentation produced by the elective system in colleges like Dartmouth. Too often, it is said, the curriculum fails to provide experiences linking different disciplines in a coherent way. As a response to this concern, The Nature of Human Nature is a major curricular experiment developed at Dartmouth College. Designed for juniors and seniors, The Nature of Human Nature is intended to show the complex relationships between evolutionary biology, genetics, human evolution, political theory, and contemporary ethical issues. More simp$l y$, it is an inquiry based on the Socratic injunction: "Know thyself."

The current generation will have the awesome possibility of changing the direction of human evolution. Modern biology has transformed our knowledge of genetics, and human evolution is understood in more detail than ever before. Biomedical technologies advance at a dizzying rate. But will the species survive? How does our evolutionary past illuminate the problems of the present and the challenge of the future? What are the philosophical, political, and ethical implications of contemporary research in the life sciences? The Nature of Human Nature is designed to enable students to confront such questions.

Three new courses have been created as an integrated program to be taken as a package: Biology 16, Evolutionary Genetics and Humans; Anthropology 16, Biological Basis of Human Behavior; and Government 26, Evolutionary Theory, Politics, and Ethics.

Biology 16 begins with a survey of human genetics and a description of the methods used to analyze the inheritance of simple and complex traits. Included is a discussion of modern genetic engineering and its applications to humans. Next, the neo-Darwinian theory of evolution is considered, with emphasis on the kinds of evidence that can be used to confirm or disprove its theoretical assumptions. Finally, we examine the validity of sociobiological theories that claim that many facets of human nature and society are genetically evolved traits.

Anthropology 16 focuses upon the evolution of human behavior. The paleontological evidence for hominid evolution is studied with emphasis on its behavioral implications. Varied interpretations of this evidence relating the coevolution of genes and culture are evaluated in light of com. peting theoretical constructs. This inquiry is grounded in the present with cross-cultural analysis of selected human behavioral characteristics, e.g., incest avoidance, gender assymetries, and kin-based social units, that frequently have been held to manifest specific genetic predispositions. Finally, the different kinds of evidence that might illustrate the nature of the interaction between genes and culture are critically examined.

Government 26 focuses on the ways that "human nature" has been related to ethics and politics since the ancient Greeks. Almost every major thinker has had some understanding of the natural grounds of political obligation and social institutions. Texts to be studied and compared with contemporary scientific approaches include Antiphon the Sophist's On Truth, Plato's Republic, and Rousseau's Discourses on the Origins of Inequality, as well as selections from Aristotle's Politics, Hobbes's Leviathan, and Marx's German Ideology. Particular attention will be given to recent developments linking evolutionary theory to the analysis of human cultural behavior, politics, and ethics.

Each course is open only to juniors and seniors also enrolled in the others. To ensure that all participants have a common background, there are two prerequisites, one course covering contemporary evolutionary biology and another in political theory. Students are required to attend all classes, which are not formally divided by subject matter. Classes and reading are planned as a coherent whole, but distinct assignments are given for each of the courses, and students receive three distinct grades.

Roger Masters Dartmouth College 